\title{
Optimisation of the thermal and structural performance of an integrated patio door
}

\author{
Adam Ellery $^{1} \quad$ Nev Fowkes ${ }^{2} \quad$ Wang Jin $^{3}$ \\ Andrew Macfarlane ${ }^{4} \quad$ Glen Pacholke $^{5}$ \\ Ravindra Pethiyagoda ${ }^{6} \quad$ Phil Stewart $^{7} \quad$ Phil Watson $^{8}$ \\ Andy Wilkins ${ }^{9} \quad$ Ayham Zaitouny ${ }^{10}$
}

(Received 17 March 2015; revised 26 June 2016)

\begin{abstract}
Frames for glass doors and windows need to be designed to be both thermally insulating and structurally strong, and there are computer programs which accurately determine the required properties. However, these programs are complex and expensive to use and are not useful for initial design work. By identifying the structural and insulating roles of the various layers within the frames we obtain simple results for the thermal transmittance and structural properties of frames. These results can be used for design guidance. More accurate (but still simple) results were obtained and coded in Excel for easy processing.
\end{abstract}

http://journal.austms.org.au/ojs/index.php/ANZIAMJ/article/view/9407 gives this article, (c) Austral. Mathematical Soc. 2016. Published June 28, 2016, as part of the Proceedings of the 2014 Mathematics and Statistics in Industry Study Group. ISSN 1445-8810. (Print two pages per sheet of paper.) Copies of this article must not be made otherwise available on the internet; instead link directly to this URL for this article. 
Subject class: 74B05; 80A20

Keywords: Heat transfer; Linear elasticity; Doors and Windows

\section{Contents}

1 Introduction

M31

2 Insulation issues

M33

2.1 Heat exchange into a room . . . . . . . . . . M34

2.1.1 Heat transfer across glazed surfaces . . . . . . . M36

2.2 Frame heat transfer rates . . . . . . . . . . . . M38

2.3 A more accurate frame heat transmission model . . . . . . M42

3 Structural issues

M44

3.1 Geometries and loading scenarios . . . . . . . . . . M45

3.2 Notation and some other definitions . . . . . . . . . . M45

3.3 Euler-Bernoulli results . . . . . . . . . . . . . . . M48

3.4 The neutral axis. . . . . . . . . . . . . . . . M49

3.5 An example .................... M50

4 Conclusions

M52

References

M55

\section{Introduction}

Centor produces large glass doors, panels and windows primarily for the luxury household market, nationally and internationally. Typically clients want uninterrupted views to the outside world spanning large lengths of their external walls; however, the constraints of structural integrity, safety and functionality mean that structural components (door, frames, etc.) are 
required, and need to be designed appropriately. The primary design issues are insulation (one would like to reduce the heat flow across the components), and structural integrity (one would like to increase the strength, and decrease the flex, sag, or bend). Of particular concern is the ability of the structures to withstand wind forcing. The frames of interest consist of aluminium, plastic and wood components with important air gaps, and are of complex design. Aluminium is used because of its structural strength but light weight, but its high conductivity is a problem for insulation. Air and plastic are very good insulators but are structurally weak. Wood is both strong and a good insulator but relatively heavy. The final product is necessarily a compromise.

There are well established methods and software packages to calculate the desired thermal and structural properties of door frames, but these are both expensive and time consuming to use during the early design phase, and they do not provide useful design insight. With this in mind Centor asked MISG2014 to develop simple and reasonably accurate rules-of-thumb, or formulae, or software, etc, that would help them rapidly design structurally sound and thermally insulating door frames.

Section 2 addresses insulation issues. First, in Section 2.1, estimates are made of the various heat transfer components into a room; frame design issues arise only if the heat flow through the frames are relatively significant compared with the other components. In Section 2.2 frame design issues are examined. As indicated earlier the frames are of complex design. Efficient insulation design requires that there be an insulating layer within the frame, and by identifying and quantifying the heat transfer across this layer the heat transfer model is greatly simplified. A slightly more complex model that employs Excel as its design tool is presented in Section 2.2.

Section 3 addresses structural issues. Results from Euler-Bernoulli beam theory are used to determine the deflections and stresses associated with various forcing and support scenarios. The frames need to be designed to withstand the associated bending forces, and the location and thickness of the stiff aluminium outer layer normally present in the frame is the dominant 
structural feature, see Section 3.5. A simple frame model is set up to determine how the stress levels are affected by frame design, and the results are programmed in Excel.

There are further brief comments and suggestions in Conclusions, Section 4.

\section{Insulation issues}

The International Organization for Standardization (ISO) is a worldwide federation of national standards bodies (ISO members). The work of preparing standards is carried by ISO technical committees and the resulting standards are published after confirmation by the parent body. The standards for windows, draws and shutters are contained in a series of documents covering all aspects of design including numerical methods and reference thermal input data (conductivities, emissivities, heat transfer coefficients for various lines, surfaces and cavities) to be used to determine the transmittance of the various components and whole products [2, 3, 4]. These programs assume steady state conditions with heat flow occurring mainly perpendicular to a plane parallel to the external and internal surfaces. For the time spans and items of interest these approximations are sensible and the results obtained have been experimentally verified. The data required to implement the associated programs needs to be provided in detailed CAD format; a typical input is displayed in Figure 1.

The problem Centor faces is not that the thermal exchange processes are modelled incorrectly but that the results are not easily interpreted and thus are not useful for the initial rough design purposes. The need to prepare detailed input, together with the turn-around time required to process the results (days to weeks), also means that the design process is both inefficient and expensive $^{1}$. The aim of this section to produce a simplified set of procedures in

${ }^{1}$ The standards documents state that they were intended for computational use and as such were never really intended as a simplified calculation procedure. 
Figure 1: A door frame: CAD input for transmittance calculations.

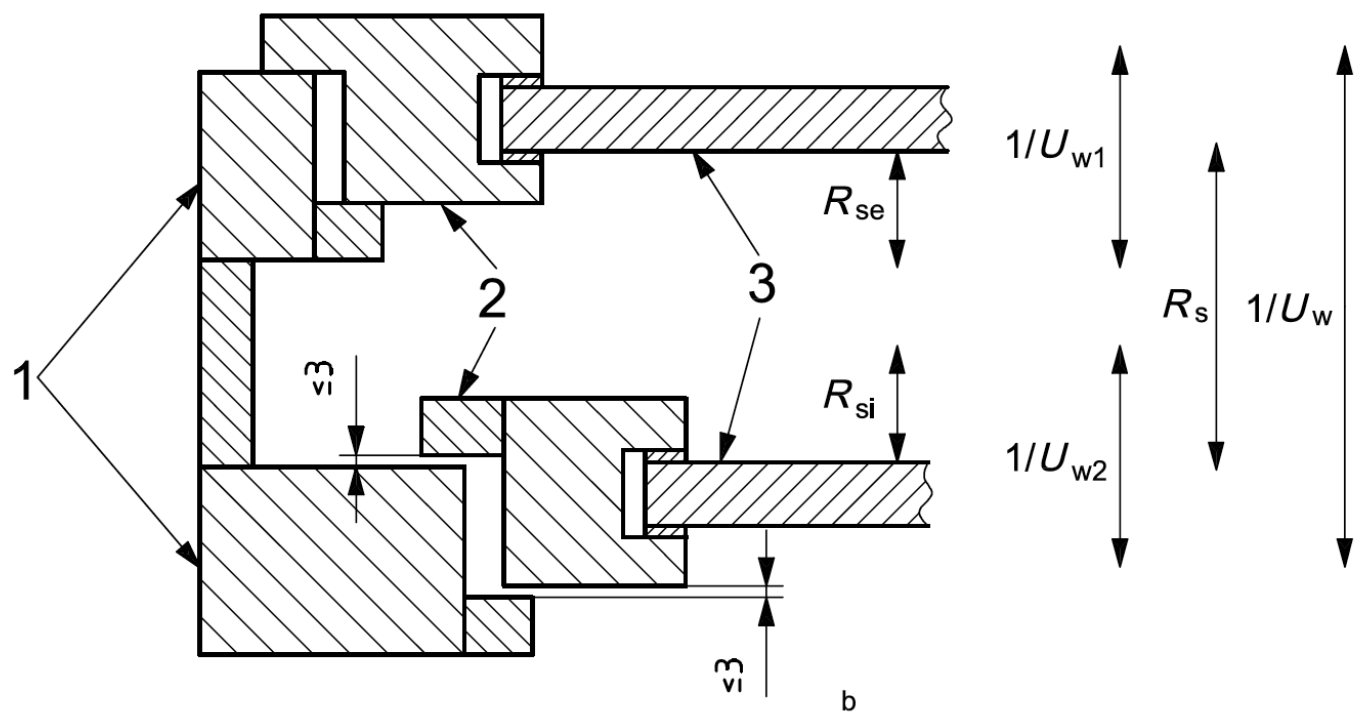

the insulation context for Centor. It is envisaged that design fine-tuning and verification would be achieved using the more accurate standards procedures.

\subsection{Heat exchange into a room}

It is useful to set the insulation issue in its architectural context.

The heat flow (in Watts) into a room of volume $V_{0}$ from the outside can broken up into the various contributions

$$
\mathrm{Q}_{\text {total }}=A_{\text {walls }} q_{\text {walls }}+A_{\text {glass }} q_{\text {glass }}+A_{\text {frames }} q_{\text {frames }}+A_{\text {gaps }} q_{\text {gaps }}+\cdots,
$$

where the q's are heat fluxes $\left(\mathrm{W} / \mathrm{m}^{2}\right)$ and the $A$ 's are the associated projected areas (the frames, the glass, the air gaps) ${ }^{2}$, and where the ellipsis $\cdots$ refers

${ }^{2}$ The solar input through the windows is normally accounted for separately. 
Figure 2: Heat transfer into a room.

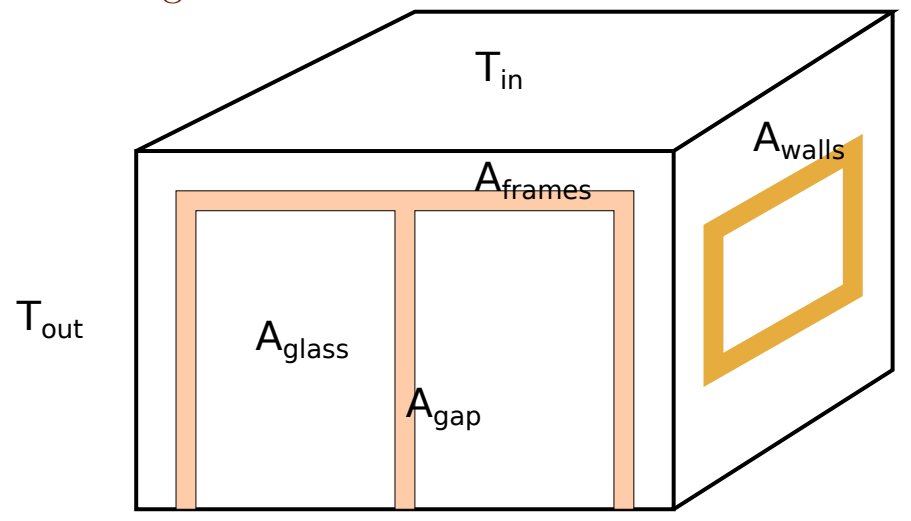

to ceiling, floor and other contributions (not of central interest here), see Figure 2.

This result can be used to determine the temperature change within the room over a time of period $t_{0}$ (typically $1 / 2$ day)

$$
\Delta \mathrm{T}_{\text {in }}=\mathrm{Q}_{\text {total }} \mathrm{t}_{0} /\left(\mathrm{V}_{0} \rho_{\mathrm{a}} \mathrm{c}_{\mathrm{p}}\right),
$$

in order to assess the effectiveness of various insulation schemes. Now

$$
\begin{aligned}
& q_{\text {walls }}=k_{\text {walls }}\left[\frac{T_{\text {out }}-T_{\text {in }}}{h_{\text {walls }}}\right] \text {, etc., so } \\
& Q_{\text {total }}=\left[\frac{A_{\text {walls }} k_{\text {walls }}}{h_{\text {walls }}}+\frac{A_{\text {glass }} k_{\text {glass }}}{h_{\text {glass }}}+\frac{A_{\text {frames }} k_{\text {frames }}}{h_{\text {frames }}}+\cdots\right]\left(T_{\text {out }}-T_{\text {in }}\right),
\end{aligned}
$$

where k's and h's are the effective conductivities and thicknesses of the various components, and where for the present we ignore the non-conductive components. For the above conductive components the heat flow rate scales up with the temperature difference across the component so that the insulation effectiveness is conveniently measured in terms of the heat flux per unit temperature difference across the product and is measured in $\mathrm{W} /\left(\mathrm{m}^{2} \mathrm{~K}\right)$. This 
measure is referred to as the transmittance (or $\mathrm{U}$ value for short) and is the reciprocal of the thermal resistance $R$. Thus

$$
\mathrm{u}=\frac{\mathrm{k}}{\mathrm{h}},
$$

and the total (or average) $\mathrm{U}$ value for the room is defined by

$$
u_{\text {total }}=\frac{Q_{\text {total }}}{A_{\text {total }}\left(T_{\text {out }}-T_{\text {in }}\right)} \equiv \frac{\sum U_{i} A_{i}}{\sum_{i} A_{i}},
$$

with the individual components

$$
\mathrm{U}_{\text {frame }}=\frac{\mathrm{Q}_{\text {frame }}}{\mathrm{A}_{\text {frame }}\left(\mathrm{T}_{\text {out }}-\mathrm{T}_{\text {in }}\right)} \equiv \frac{\mathrm{k}_{\text {frame }}}{\mathrm{h}_{\text {frame }}} \equiv \frac{1}{\mathrm{R}_{\text {frame }}}, \ldots
$$

A window as normally bought in a showroom consists of a pane of glass together with its frame, as well as the wall components, so it is normally useful to refer to the combined transmittance of the product obtained by summing the various contributions. Here we work in terms of simpler (glass, frame) components. Typical $\mathrm{U}$ values $\left(\mathrm{W} \mathrm{m}^{-2} \mathrm{~K}^{-1}\right.$ ) are 0.25 for well insulated walls, 5.7 for single glazing, 4.5 for single glazing with frames, 2.2 for double glazing with frames reducing to 1.2 if advanced coatings are used. For triple glazed windows 0.8 is typical.

Areas and conductivities of materials used in fenestration structures are typically either 'very large' or 'very small', but it is important to note that it is the $(A k / h) \equiv U A$ combination that determines the relative effect of the components on the temperature rise within the room $\Delta \mathrm{T}_{\text {in }}$, see (1).

\subsubsection{Heat transfer across glazed surfaces}

The heat flux $\mathrm{q}_{\text {glass }}$ through a single window pane due to a temperature drop $\left(T_{\text {out }}-T_{\text {in }}\right)$ across the pane (including the convection boundary layers) is given by

$$
\left(T_{\text {out }}-T_{\text {in }}\right)=R_{1} q_{\text {glass }},
$$


where the resistance to flow,

$$
\mathrm{R}_{1}=\left[\frac{1}{\mathrm{H}_{\mathrm{ex}}}+\frac{1}{\mathrm{H}_{\text {in }}}+\frac{\mathrm{h}_{\text {glass }}}{\mathrm{k}_{\text {glass }}}\right]
$$

is made up of three series components: convective flow from the external environment to the pane, conductive flow through the glass, and convective flow to the internal environment. While the heat transfer coefficients $\mathrm{H}_{\text {out }}$ and $\mathrm{H}_{\text {in }}$ depend on environmental conditions such as wind speeds, standard values of $\mathrm{H}_{\text {out }}=23 \mathrm{~W} /\left(\mathrm{m}^{2} \mathrm{~K}\right), \mathrm{H}_{\text {in }}=8 \mathrm{~W} /\left(\mathrm{m}^{2} \mathrm{~K}\right)$ are used for $\mathrm{U}$ evaluations. The resistance to flow through the glass of thickness $6 \mathrm{~mm}$ is $h_{\text {glass }} / k_{\text {glass }}=$ $6 \cdot 10^{-3}$, which is much less than the convective components $\left(\frac{1}{\mathrm{H}_{\text {in }}}=\frac{1}{8}\right.$ and $\frac{1}{\mathrm{H}_{\text {out }}}=\frac{1}{24}$ ), so that external convective heat processes (especially within the room) primarily determine the flow of heat through the pane. Using these values results in

$$
\mathrm{U}_{\text {glass } 1}=\frac{1}{\mathrm{R}_{1}}=5.8 \approx \mathrm{H}_{\text {in }},
$$

which is taken as a standard for $\mathrm{U}$ evaluations [2].

The resistance to heat flow across double glazing is

$$
\mathrm{R}_{2}=\left[\frac{1}{\mathrm{H}_{\mathrm{ex}}}+\frac{1}{\mathrm{H}_{\mathrm{in}}}+2 \frac{\mathrm{h}_{\text {glass }}}{\mathrm{k}_{\text {glass }}}+\frac{\mathrm{h}_{\mathrm{air}}}{\mathrm{k}_{\mathrm{air}}}\right] .
$$

Now $h_{\text {air }} / k_{\text {air }}=0.66\left(\right.$ with $h_{\text {air }}=16 \mathrm{~mm}$ ) which is significantly greater than $1 / \mathrm{H}_{\text {in }}$, and much greater than the other resistances, so that in this case it is the resistance to heat flow across the air gap between the panes that dominates, and the air gap thickness is the important parameter. This results in

$$
\mathrm{U}_{\text {glass } 2}=1.19 \approx \frac{\mathrm{k}_{\mathrm{air}}}{\mathrm{h}_{\mathrm{air}}}=\mathrm{U}_{\mathrm{air}},
$$

which is taken as a standard. Convective flows will be set up within this air gap if it is too large which limits the thickness to about $20 \mathrm{~mm}$.

In both the above situations the heat transfer occurs across resistances in series, and because one of the resistances was much larger than the others, 
Table 1: Physical and thermal properties of frame materials. (as taken from ISO 2003).

\begin{tabular}{lcc}
\hline Material & $\begin{array}{c}\text { Conductivity } \\
\mathrm{k} \text { in } \mathrm{W} /(\mathrm{m} \mathrm{K})\end{array}$ & $\begin{array}{c}\text { Thickness } \\
(\boldsymbol{w}, \mathrm{h}) \mathrm{mm}\end{array}$ \\
\hline air & 0.024 & 20,60 \\
argon & 0.016 & 8 \\
wood & 0.18 & 20 \\
polyvinalchloride & 0.17 & 2 \\
glass & 1.0 & 6 \\
aluminium & 160. & 2 \\
\hline
\end{tabular}

the other components could be ignored leading to greatly simplified results; this simplification will be a recurring theme.

\subsection{Frame heat transfer rates}

As indicated earlier frame design is a central issue, and, because of conflicting strength and insulation requirements, both metals and non-metals are used, and designs are complex. The thermal properties of the most widely used components are given in Table 1.

The conductivity of aluminium is roughly $10^{3}$ times that of the wood and plastic, which are in turn ten times greater than air. Thus even the thin strips of aluminium that are structurally preferred (being both light and strong) can contribute significantly to the heat transfer across the fenestration structure if the strips bridge the structure. Sensible insulation design requires that such bridges not be present, and this is the case for the frames examined. A typical frame section is displayed in Figure 3. There are (almost completely enclosed) upper and lower aluminium boxes separated by a centre box with plastic ends (and aluminium top and bottom). Because of the high conductivity of 
Figure 3: A typical frame section. The blue regions correspond to aluminium strips, the grey regions to plastic strips. The aluminium strips do not bridge the frame so that there is a barrier to the flow of heat across the structure. $\left(w_{\mathrm{p}}=2 \mathrm{~mm}, \boldsymbol{w}_{\text {air }}=60 \mathrm{~mm}, \mathrm{~h}_{\text {air }}=20 \mathrm{~mm}\right)$.

\section{outside}

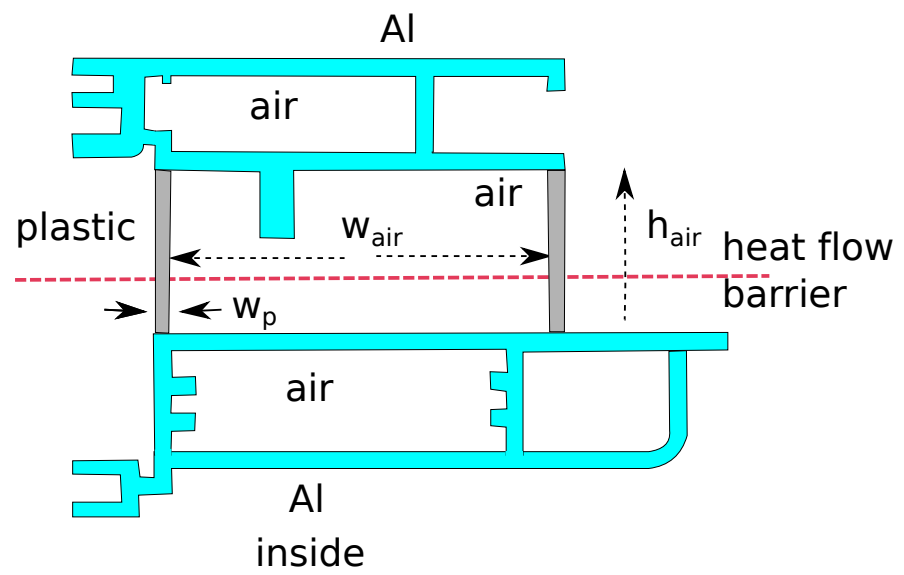

aluminium the temperature in the upper box (with the enclosed air) will be almost uniform and at the same as that of the outside $T_{\text {out }}$, and similarly the lower box will be at the temperature $T_{\text {in }}$, see Figure 4 .

The plastic sided box in the centre is air filled and will present a thermal barrier to the flow of heat so that most of the temperature drop $\left(T_{\text {out }}-T_{\text {in }}\right)$ will occur across this layer; the approximate temperature profile will be as in Figure 4. The heat flow rate per unit frame length across this heat barrier is obtained by adding together the plastic and air contributions to give the approximate result

$$
\begin{aligned}
& {\left[\frac{k_{\text {frame }} w_{\text {frame }}}{h_{\text {air }}}\right]\left(T_{\text {out }}-T_{\text {in }}\right),} \\
& \text { where } \quad k_{\text {frame }}=\left[\frac{2 k_{p} w_{p}+k_{\text {air }} w_{\text {air }}}{w_{\text {frame }}}\right], \quad w_{\text {frame }}=2 w_{p}+w_{\text {air }} ;
\end{aligned}
$$


Figure 4: An approximate model for heat transfer through the frame. Left: The physical model. The blue regions correspond to aluminium strips, and the grey to plastic strips. Right: The real and approximate temperature profiles through the frame.

\section{Temp variation through the frame}
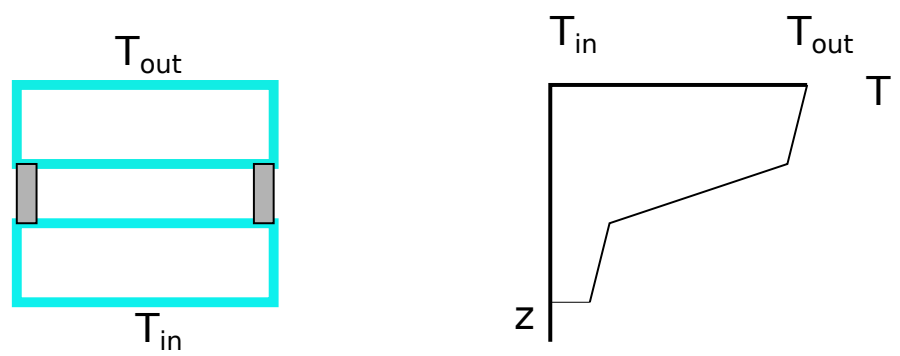

\section{replace by:}
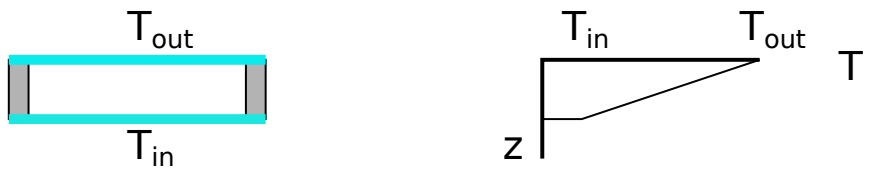

here $\left(k_{p}, w_{p}\right)$ and $\left(k_{\text {air }}, w_{\text {air }}\right)$ are the thicknesses and conductivities of the plastic strip and air respectively, and $k_{\text {frame }}$ defines the effective conductivity of the frame. We have

$$
\mathrm{U}_{\text {frame }}=\frac{k_{\text {frame }}}{h_{\text {air }}} \text {, and } \quad Q_{\text {frame }}=U_{\text {frame }}\left(l_{\text {frame }} \mathcal{W}_{\text {frame }}\right)\left(T_{\text {out }}-T_{\text {in }}\right)
$$

where $l_{\text {frame }}$ is the length of the frame.

Using (4), (5), (2), and (3) we determine the relative size of the heat flow rate contributions into a room due to the frame and the $2 \mathrm{~m}$ square glazed panel shown in Figure 5.

The proportional contributions to the heat transfer across the fenestration structure consisting of rectangular glazed area surrounded by a frame of 
Figure 5: The panel consists of a square single or double sheet of glass (left) surrounded by four pieces of frame of the type shown in Figure 3.
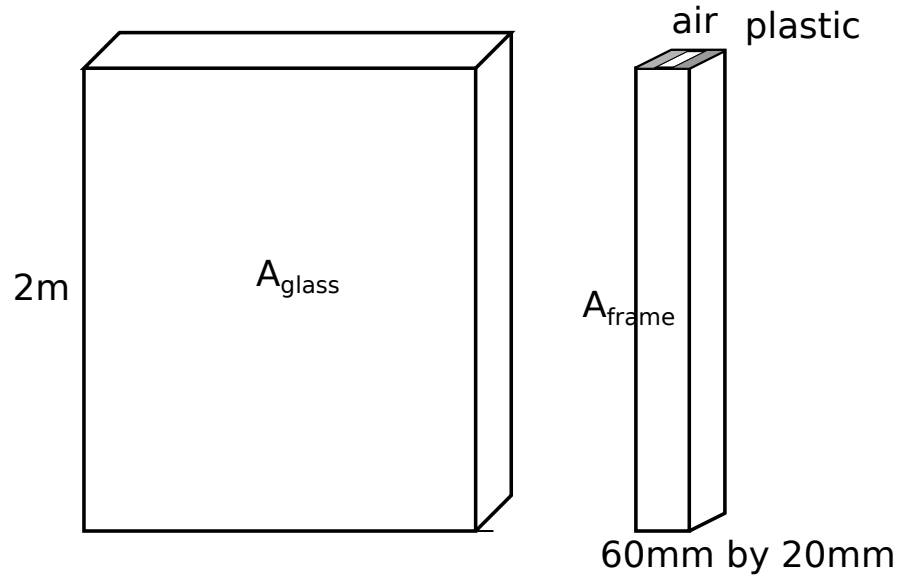

length $l_{\text {glass }}$ shown in Figure 5 are

$$
\frac{\mathrm{Q}_{\text {frame }}}{\mathrm{Q}_{\text {glass }}}=\left(\frac{w_{\text {frame }} l_{\text {frame }}}{A_{\text {glass }}}\right)\left(\frac{\mathrm{U}_{\text {frame }}}{\mathrm{U}_{\text {glass }}}\right),
$$

where the competing features are separated out. The $U$ value for this frame is $\mathrm{U}_{\text {frame }}=1.656$, so that the $\mathrm{U}$ value ratio is $(1.65 / 5.7)=0.29$ for the single glazed case, and $(1.65 / 1.19)=1.39$ for the double glazed case. Of more importance is the $\mathrm{Q}$ ratio. For the prescribed panel the frame to glass area ratio is 0.12 so that the $\mathrm{Q}$ ratio is $0.12 \times 0.29=0.035$ for the single glazed case, and $0.12 \times 1.39=0.17$ for the double glazed case. Thus the frame contributes just $3 \%$ to the heat flow in the single frame case, and about $20 \%$ in the doubly glazed case. Evidently the frame is over-designed for single glazing in this case and is marginally over-designed for double glazing. For double glazing a $50 \%$ reduction in the $\mathrm{U}$ value is achieved by using special coatings so that for such a situation the heat flow through the two components is comparable, and good frame design is essential.

An improvement in insulation design for the frame examined requires a 
modification of the insulation box. Plastic is required to enclose the air, but it is a poor insulator compared with air. The ratio of contributions to the heat transport across the box is $2 \mathrm{k}_{\mathrm{p}} w_{\mathrm{p}} /\left(w_{\text {air }} \mathrm{k}_{\text {air }}\right) \approx 0.47$; this is significant. Reductions in the thickness of the plastic strips would affect the $U$ value of the frame, but plastic is not a robust material so reducing the thickness could compromise its long term usefulness; plastic degenerates over time. It would appear that increasing the size of the air zone is the way to improve performance.

The frame area as described above only includes the plastic sided box; other elements of the frame (for example facing material) are excluded because they do not significantly effect the thermal performance of the structure.

\subsection{A more accurate frame heat transmission model}

A frame generally consists of distinct horizontal layers (of thickness $h_{\mathfrak{i}}$ ) parallel to the inner and outer surfaces, with each layer consisting of vertical strips/ slabs of different thickness $w_{i}$ and conductivities $k_{i}$. The associated heat flow path-ways with their conductive strengths $\left(w_{i} k_{i}\right)$ for such a frame are displayed in Figure 6 Left.

This complex system is resolved into a simpler system by first resolving the horizontal layers using the resistors in parallel result

$$
\kappa_{\text {layer }}=\frac{\sum_{i} w_{i} k_{i}}{\sum_{i} w_{i}} ;
$$

this produces the equivalent in series system depicted in Figure 6 Right. The conductivity of the frame is then calculated using the resistors in series result

$$
k_{\text {frame }}=\frac{\sum_{j} h_{j}}{\sum_{j} \frac{h_{j}}{k_{j}}} .
$$

For the setup depicted in Figure 6 Left, region 2 is the insulating layer and the other layers are conducting layers and the resolved series system is shown 
Figure 6: Left: A representation of the conductive heat transport paths through parallel layers of a frame. The thickness of the vertical lines is proportional to the effective conductivities $\left(k_{1} w_{i}\right)$ of the paths. Right: The equivalent series heat transfer system.
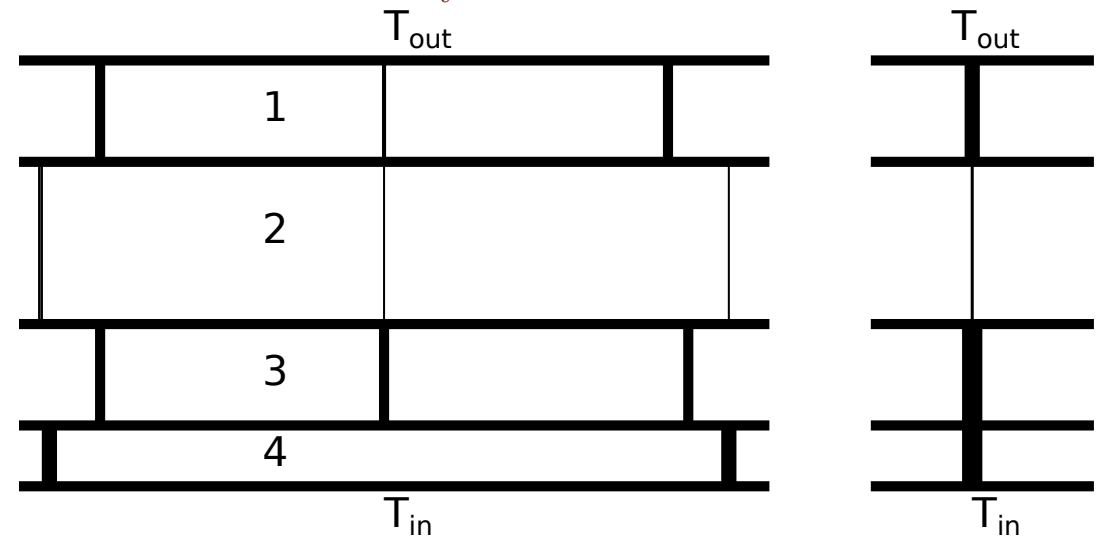

in Figure 6 Right. As indicated earlier for well designed frames the resolved series may be then well approximated by a single conductor corresponding to the insulating layer 2. The above resolution process is the procedure used within the Excel worksheet.

The resolution procedure just described assumes the heat transfer primarily occurs at right angles to the external surfaces, with constant temperature profiles parallel to these surfaces. Given the thin geometry and insulation objectives it makes sense to use designs that obey these requirements. However, structural considerations suggest the use of 'ribs' (to improve rigidity) that produce significant heat transfer parallel to the surface. For example for the frame depicted in Figure 3 the rib in the insulation layer marginally changes the effective thickness of the zone and compromises the insulation efficiency of this layer. The introduction of an additional 'rib layer' improves the approximation; some care is required when using the Excel results which will generally be very reliable and more accurate than the earlier crude results. 
Figure 7: A uniform wind loading is applied to a door causing the frame (and the glass) to deform.

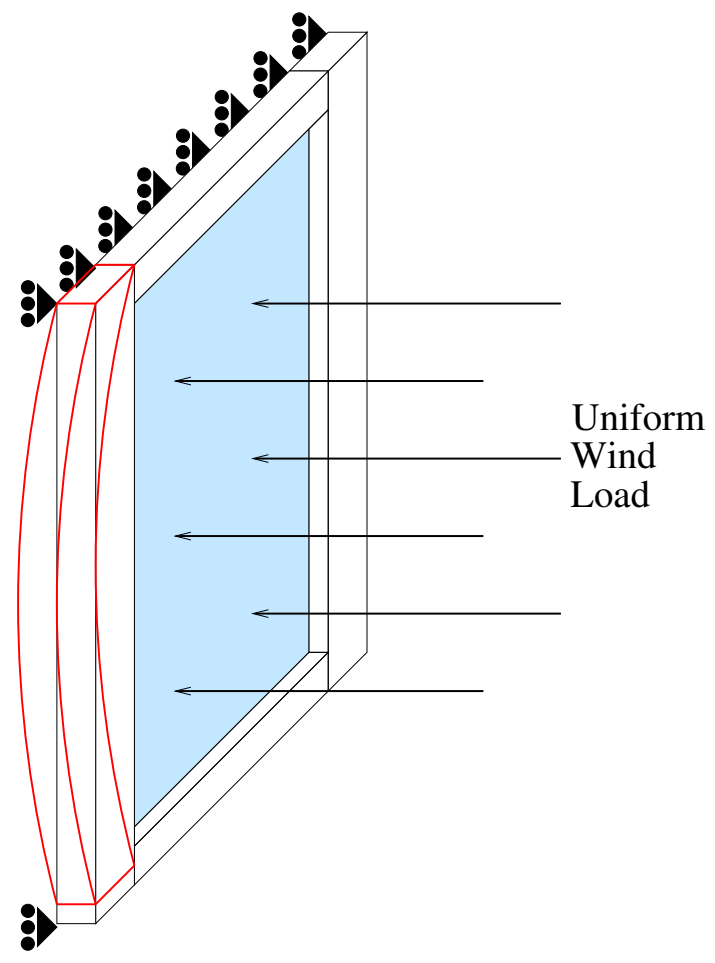

\section{Structural issues}

Centor must ensure that their doors are structurally sound. Here we concentrate on modelling the door's response to a load induced by the wind applied uniformly upon the face of the door, which is the typical loading configuration considered by standards authorities, see Figure 7. We develop formulae for the maximum deflection, the maximum tensile stress in each door component and the maximum shear stress in each door component. Standards in some countries state that the maximum deflection should not exceed a specified value. The maximum stress components are used to determine whether a 
particular component (aluminium, wood, glue, etc) will fail.

\subsection{Geometries and loading scenarios}

We model the deformation of the frame-plus-glazing using Euler-Bernoulli beam theory. The theory holds under 1D deflection conditions, providing the deflections are relatively small compared with the beam length, and providing buckling and plastic deformation do not occur. From a practical point of view, the design has to avoid these circumstances, which means that practical (design) limits are placed on the size of the stresses and displacements as predicted by the theory. The deflection of the panel and the stress levels within the frame are dependent on the manner in which the pane is supported around its frame edges. A variety of support mechanisms in common use are shown in Figure 8.

Here we concentrate our attention on failure of the frame, since the glass is much less rigid than the frame and acts to distribute wind load onto the frame.

\subsection{Notation and some other definitions}

We use the following notation: $w$ is a uniform load-per-height; and $l$ is the glass-and-frame height. As also shown in Figure 8 we define a Cartesian coordinate system $(x, y, z)$ in which the $x$ axis runs up the length of the door ( $l$ ), the $y$ axis is normal to the glass pane, and the $z$ axis runs along the door's base.

Figure 9 shows a cross-section. The glass-and-frame (beam) is constructed from different materials running though the thickness so that the Young's modulus $\mathrm{E}=\mathrm{E}(\mathrm{y}, z)$.

The frame resists deflection by bending around the neutral axis $y=y_{c}$ whose 
Figure 8: Four loading scenarios considered in this report, called (clockwise from top left): cantilever, two rollers, fixed ends, and fixed + roller (see also Table 2). In each, a uniform load $w(\mathrm{~N} / \mathrm{m})$ is applied to the door frame. The frame has height $l$ (typically $2.5 \mathrm{~m}$ ). Hence the total force applied is $w l$. The glass-and-frame has thickness (which is typically around $30 \mathrm{~mm}$ for the glass and $60 \mathrm{~mm}$ for the frame), which is much less than $l$.
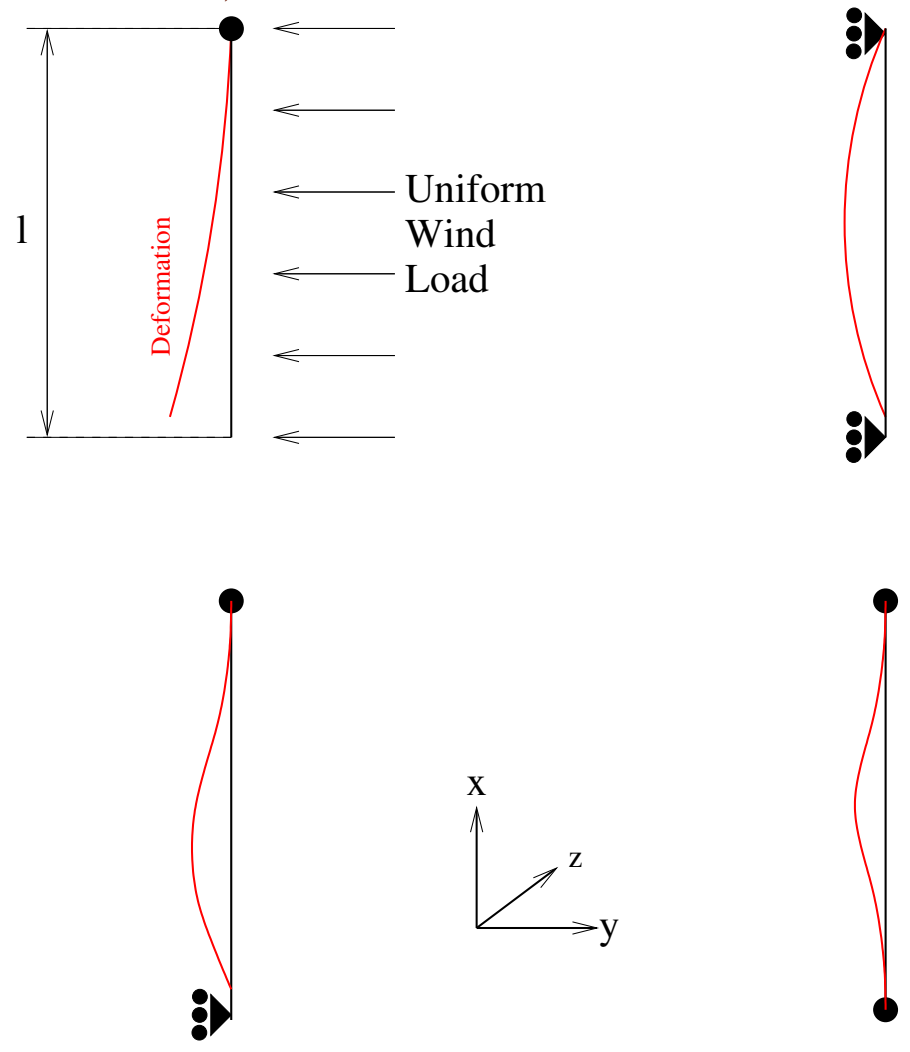
Figure 9: A hypothetical glass-and-frame cross section. The 3D structure is a prismatic solid, extruded from this $(y, z)$ cross section. Different materials are used in the construction of the 3D structure.

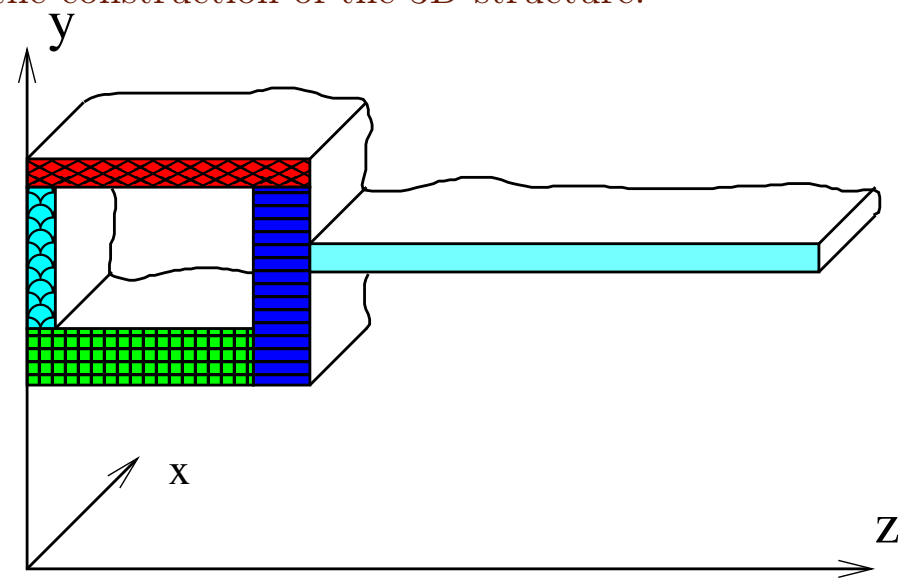

location depends on its elastic structure and is

$$
0=\int E(y, z)\left(y-y_{c}\right) d A
$$

where the integral is performed over the $(y, z)$ cross section. The bending moment $M$ acting on the frame depends on the area moment of inertia I:

$$
M(x)=E I \frac{d^{2} u(x)}{d x^{2}}, \quad \text { where } \quad E I=\int E(y, z)\left(y-y_{c}\right)^{2} d A
$$

and $u(x)$ is the beam displacement. In the case where $E$ is constant, $E I$ is the product of the Young's modulus and the moment of inertia of the cross section about $y=y_{c}$.

The shear stress in the beam depends on three other related quantities, which all involve integrals of $E(x, y)$. The shear stress is given on the line $y=\bar{y}$, for user-specified $\bar{y}$. We denote by $\bar{y}_{c}$ the "effective centroid" of a part of the 
beam with $y>\bar{y}$. This gives

$$
0= \begin{cases}\int_{y>\bar{y}} E(y, z)\left(y-\bar{y}_{c}\right) d \bar{A} & \text { for } \bar{y} \geqslant y_{c}, \\ \int_{y<\bar{y}} E(y, z)\left(y-\bar{y}_{c}\right) d \bar{A} & \text { for } \bar{y}<y_{c},\end{cases}
$$

where the $d \bar{A}$ represents the integral over the relevant partial area. Let the "effective breadth" of the part of the beam with $y=\bar{y}$ be

$$
\overline{\mathrm{bE}}=\int_{y=\bar{y}} \mathrm{E}(\mathrm{y}, z) \mathrm{d} z .
$$

Furthermore, let the "effective area" of the section $y>\bar{y}$ be

$$
\overline{A E}= \begin{cases}\int_{y>\bar{y}} E(y, z) d \bar{A} & \text { for } \bar{y} \geqslant y_{c}, \\ \int_{y<\bar{y}} E(y, z) d \bar{A} & \text { for } \bar{y}<y_{c} .\end{cases}
$$

\subsection{Euler-Bernoulli results}

Now that all the notation and some formulae have been defined, EulerBernoulli beam theory [1] is invoked to yield the desired results. The maximum deflection of the beam is

$$
u_{\max }=w \frac{f(l, \ldots)}{E I}
$$

where $f$ is a function that is dependent on the loading scenario (see Table 2). Furthermore, the maximum tensile stress as a function of $y$ is

$$
\sigma_{x x}^{\max }=\frac{E(y, z)\left(y-y_{c}\right) B_{\max }}{E I},
$$

and the maximum shear stress at $y=\bar{y}$ is

$$
\sigma_{x y}^{\max }(\bar{y})=\frac{E(y, z) V_{\max } \overline{A E}\left|\bar{y}_{c}-y_{c}\right|}{E I \overline{b E}}
$$


Table 2: Maximum deflection, bending moment and shear force for the four loading scenarios.

\begin{tabular}{|c|c|c|c|c|}
\hline Scenario & $\begin{array}{l}\text { Roark case } \\
\text { Number }\end{array}$ & $\begin{array}{l}\text { Maximum } \\
\text { deflection }(\mathrm{m}) \\
\mathrm{u}_{\max }\end{array}$ & $\begin{array}{l}\text { Max bending } \\
\text { moment }(\mathrm{N} \mathrm{m}) \\
\mathrm{B}_{\max }\end{array}$ & $\begin{array}{l}\text { Maximum } \\
\text { shear }(\mathrm{N}) \\
\mathrm{V}_{\max }\end{array}$ \\
\hline Cantilever & 3 & $\frac{w l^{4}}{8 \mathrm{EI}}$ & $\frac{w l^{2}}{2}$ & $w l$ \\
\hline Two rollers & 13 & $\frac{5 w l^{4}}{384 \mathrm{EI}}$ & $\frac{w l^{2}}{8}$ & $\frac{w l}{2}$ \\
\hline Fixed + roller & 23 & $0.0054 \frac{w l^{4}}{E I}$ & $\frac{w l^{2}}{8}$ & $\frac{5 w l}{8}$ \\
\hline Fixed ends & 33 & $\frac{w l^{4}}{384 \mathrm{EI}}$ & $\frac{w \mathrm{l}^{2}}{12}$ & $\frac{w \mathrm{l}}{2}$ \\
\hline
\end{tabular}

where $B_{\max }$ and $V_{\max }$ are the maximum bending moment and shear levels, see Table 2. EI appears in all these three formulae, $y_{c}$ appears in the last two, and the final formula contains other integrals of $E(x, y)$. Finding $E I, y_{c}$, and so on, is the subject of most of the remainder of this section.

The formulae also depend on $f$, the maximum bending moment $B_{\max }$ experienced in the beam, and the maximum shear force $V_{\max }$. Table III (pp. 114-117) of Roark [1] presents expressions for these quantities for many different loading scenarios. Roark's table also contains the deflection along the beam, slopes at the beam ends, constraining moments at the beam ends in the case of one or both ends fixed, shear forces throughout the beam and bending moments throughout the beam. The pertinent results for the scenarios of Figure 8 are listed in Table 2.

\subsection{The neutral axis}

The formulae (13)-(15) all involve integrals of the form

$$
\int E y^{n} d A .
$$


Using these integrals combined with the values found in Table 2, yields the maximum deflection of the door, the maximum tensile stress and shear stress for each component in the cross section.

The final task is therefore to compute the integrals (16). Centor's door cross sections consist of bonded components, and each component has a rectangular shape. Therefore, the integral is decomposed as a sum:

$$
\int E y^{n} d A=\sum_{\text {rectangles }} \int_{\text {rectangle }} E_{\text {rectangle }} \mathcal{y}^{n} d A_{\text {rectangle }} .
$$

For example, for a rectangle of width $s$, thickness $t$, and with centroid at $y=h$

$$
\begin{aligned}
\int_{\text {rectangle }} E_{\text {rectangle }} d A_{\text {rectangle }} & =E_{\text {rectangle }} s t, \\
\int_{\text {rectangle }} E_{\text {rectangle }} y d A_{\text {rectangle }} & =E_{\text {rectangle }} s h t, \\
\int_{\text {rectangle }} E_{\text {rectangle }} \mathcal{Y}^{2} d A_{\text {rectangle }} & =E_{\text {rectangle }} s\left(\frac{1}{12} t^{3}+h^{2} t\right) .
\end{aligned}
$$

Because of the $\mathrm{h}^{2}$ component of the last equation, the outer layers contribute much more significantly to the bending rigidity than the inner layers. For this reason the presence of a covering stiff aluminium plate (as seen in the frame displayed in the executive summary) greatly increases the rigidity of that frame system.

\subsection{An example}

Accurate numerical results have been obtained by Centor for the frame with cross-section shown in Figure 10 using a finite-element analysis of a two-roller bending test. We use this example to check the accuracy of our simplified model results. Table 3 shows the input and output data. 
Figure 10: The example cross-section from Centor. Blue material is aluminium, brown material is wood. For scale, the cross-section is $85 \mathrm{~mm}$ wide and $60 \mathrm{~mm}$ deep.

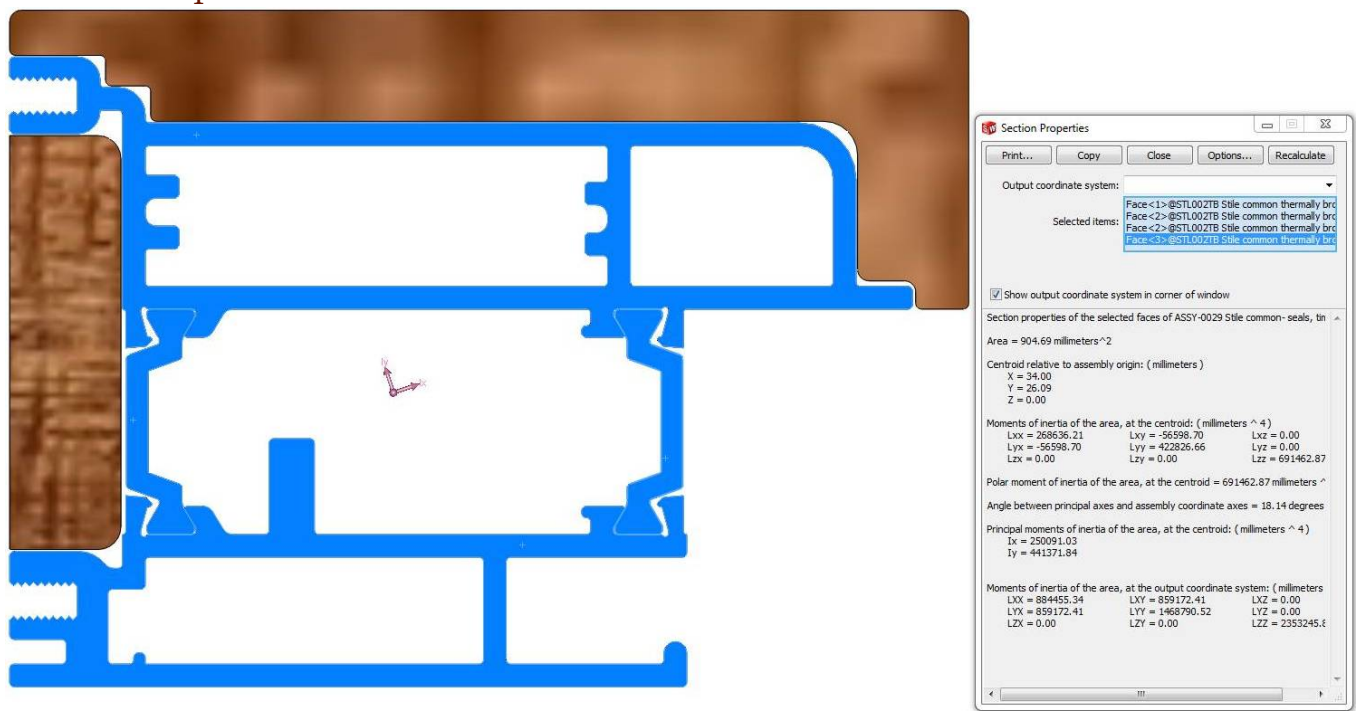

Table 3: Input and output parameters from Centor's finite-element analysis of a simply-supported bending test of beam with cross-section depicted in Figure 10.

\begin{tabular}{ll}
\hline Length of beam & $2 \mathrm{~m}$ \\
Total load applied & $1000 \mathrm{~N}$ \\
Modulus of aluminium & $69 \mathrm{Gpa}$ \\
\hline Maximum deflection & $5.6 \mathrm{~mm}$ (without timber) \\
\hline
\end{tabular}


For the two-roller bending test our simplified model gives

$$
\mathrm{u}_{\max }=\frac{5 w l^{4}}{384 \mathrm{EI}}, \quad \mathrm{B}_{\max }=\frac{w l^{2}}{8}, \quad \mathrm{v}_{\max }=\frac{w l}{2},
$$

see Table 2.

A simplified representation of the cross-section is shown in Figure 11. To illustrate the effect of different components, labels "a" through to "q" (aluminium pieces), and "1" to "3" (wood pieces) are introduced and their relative contribution to the bending rigidity is listed in Table 4 . These results were generated using Excel software created at MISG2014. The software also allows the components' relative importance to be displayed on colour-coded figures such as Figure 11 which greatly assists design. The maximum deflection is $6.13 \mathrm{~mm}$, which is an error of $9 \%$ compared to Centor's finite-element analysis based on the CAD drawing of Figure 10. As more detail was added (more tabs of Aluminium, the plastic inserts, etc), the error was decreased. Design improvements were suggested and examined using this software.

\section{Conclusions}

Any competent frame design needs to optimise both structural and insulation objectives using available materials. Efficient design is achieved by using both structurally strong materials (aluminium) and highly insulating materials (air, plastic and wood), and by separating out in different layers the structural and insulating components. By identifying the roles of various layers within the frame we were able to obtain useful insight and simplified results for the strength and thermal transmittance of frames. In addition, more general and accurate, but still simple, results were obtained and coded in Excel. Design improvements for a particular frame were suggested and examined using the Excel code; these results are not included in this report. 
Table 4: Geometry of the components shown in Figure 11. The relative importance $(\%)$ of the component's contribution to the bending rigidity is tabulated in the final two columns. These results were generated using software developed at MISG2014.

\begin{tabular}{rrrrrr}
\hline Component & $\begin{array}{l}\text { Width } \\
(\mathrm{mm})\end{array}$ & $\begin{array}{c}\text { Height } \\
(\mathrm{mm})\end{array}$ & $\begin{array}{l}\text { Distance } \\
\text { from top } \\
(\mathrm{mm})\end{array}$ & $\begin{array}{l}\text { Relative } \\
\text { importance } \\
\text { timber })\end{array}$ & \multicolumn{2}{c}{$\begin{array}{l}\text { Relative } \\
\text { importance } \\
(\%) \\
\text { timber })\end{array}$} \\
\hline $\mathrm{a}$ & 60 & 2 & 57 & 32.4 & 32.4 \\
$\mathrm{~b}$ & 75 & 2 & 10 & 27.5 & 16.6 \\
$\mathrm{c}$ & 60 & 2 & 46 & 10.7 & 12.3 \\
$\mathrm{~d}$ & 70 & 2 & 24 & 3 & 8.9 \\
$\mathrm{e}$ & 3 & 9 & 48 & 4.6 & 4.8 \\
$\mathrm{f}$ & 2 & 9 & 48 & 3 & 3.2 \\
$\mathrm{~g}$ & 2 & 12 & 12 & 2.1 & 1.1 \\
$\mathrm{~h}$ & 2 & 12 & 12 & 2.1 & 1.1 \\
$\mathrm{i}$ & 2 & 12 & 12 & 2.1 & 1.1 \\
$\mathrm{j}$ & 8 & 2 & 4 & 4.8 & 3.1 \\
$\mathrm{k}$ & 2 & 4 & 6 & 1.9 & 1.2 \\
$\mathrm{l}$ & 6 & 2 & 54 & 2.5 & 2.6 \\
$\mathrm{~m}$ & 2 & 3 & 54 & 1.3 & 1.4 \\
$\mathrm{n}$ & 3 & 2 & 15 & 0.6 & 0.4 \\
$\mathrm{o}$ & 3 & 2 & 19 & 0.4 & 0.2 \\
$\mathrm{p}$ & 3 & 2 & 15 & 0.6 & 0.4 \\
$\mathrm{q}$ & 3 & 2 & 19 & 0.4 & 0.2 \\
\hline 1 & 76 & 10 & 0 & 0 & 15.3 \\
2 & 9 & 14 & 10 & 0 & 7.1 \\
3 & 10 & 34 & 12 & 0 & 1.1 \\
\hline
\end{tabular}


Figure 11: A simplified representation of the cross-section shown in Figure 10. Some parts are not included since they add very little to the bending rigidity of the whole. This picture was generated using software created at MISG2014. The different components are coloured and numbered.

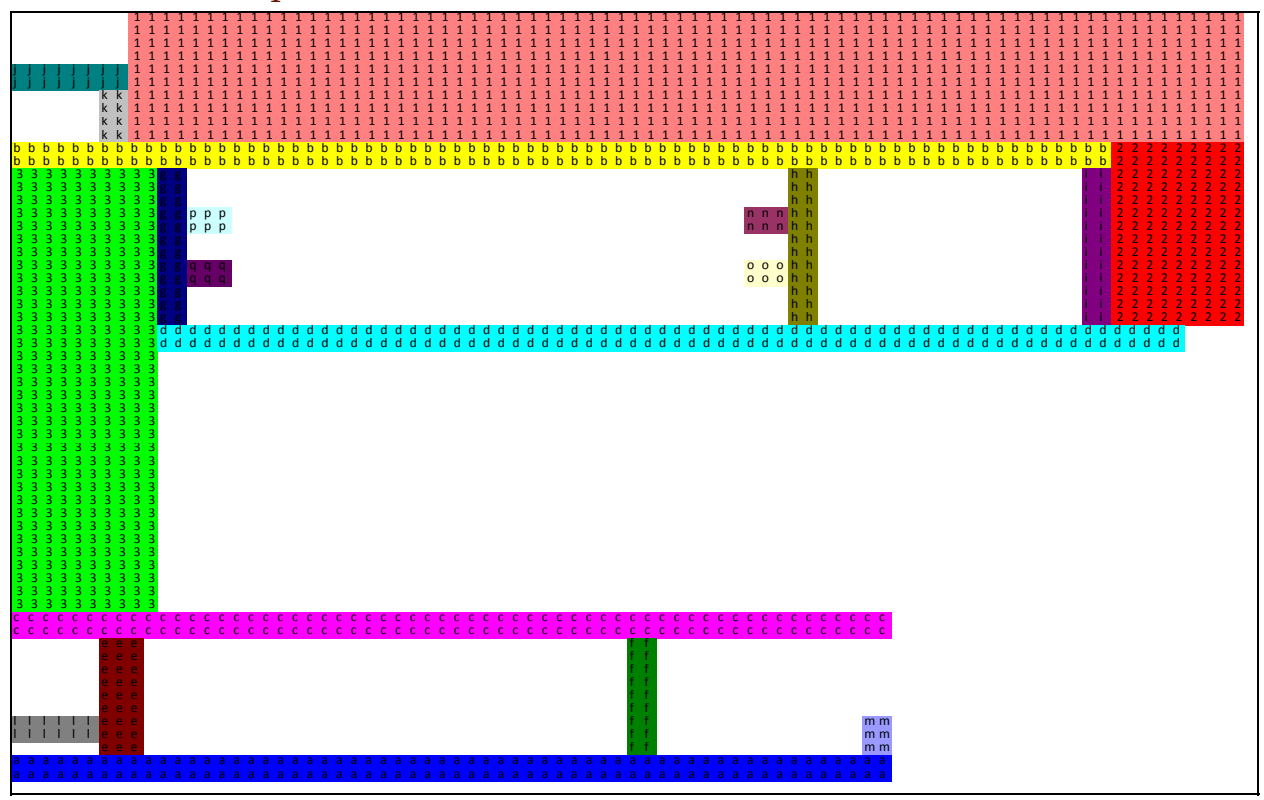

Acknowledgements We are grateful to Centor and industry representative Glen Pacholke for bringing the problem to MISG2014 and for valuable input before, after and throughout the meeting. The hospitality of our hosts at QUT was greatly appreciated, and we especially thank Troy Farrell for his advice and continued support. 


\section{References}

[1] R. J. Roark "Formulas for stress and strain" McGraw-Hill (1965), 4th ed. M48, M49

[2] "Thermal performance of windows, doors and sharing devices-Detailed Calculations". ISO 15099:2003(E) M33, M37

[3] "Thermal performance of windows, doors and shutters - Calculation of thermal transmittance - Part 2 Numerical Method for Frames". BS ENISO 10077-2-2003 M33

[4] "Thermal performance of windows, doors and sharing devices - Part 1 General". BS EN 10077-1:2006 M33

\section{Author addresses}

\section{Adam Ellery,} mailto:adam.ellery@student.qut.edu.au

2. Nev Fowkes, University of WA, Nedlands, WA 6009, AUstralia mailto:neville.fowkes@uwa.edu.au

\section{Wang Jin,}

mailto:w1.jin@qut.edu.au

4. Andrew Macfarlane, mailto: andrew. macfarlane4@bigpond.com

5. Glen Pacholke, Centor Holdings Pty Ltd, 997 Kingsford Smith Drive, Eagle Farm, Qld 4009, Australia.

http:////www. centor.com mailto:Glen.Pacholke@centor.com

6. Ravindra Pethiyagoda, mailto:ravindra. pethiyagoda@student. qut.edu. au 


\section{Phil Stewart,} mailto:phillip.stewart0@gmail.com

8. Phil Watson, mailto:pw.cmp@optusnet.com.au

9. Andy Wilkins, Queensland Centre for Advanced Technologies CSIRO, Kenmore QLD 4069, Australia.

mailto:andrew.wilikins@csiro.au

\section{Ayham Zaitouny,}

mailto:20720394@student.uwa.edu.au 